\title{
PRACTICAL COURSE OF “3S” INTEGRATED TECHNIQUE IN GIS SPECIALTY OF BEIJING NORMAL UNIVERSITY
}

\author{
H. P. Liu*, J. Qi, M. Bai \\ School of Geography, Beijing Normal University, Beijing, China (hpliu@bnu.edu.cn, qijinghao9@aliyun.com,
} 78925306@qq.com)

KEY WORDS: “3S” integrated technique, remote sensing, global positioning system, geographic information systems; field surveying

\begin{abstract}
:
Practical course is one of the characteristics of earth sciences courses at university. Student-centered method is an important idea in university teaching, and practical course should fully reflect the idea by designing courses and controlling aspects for teaching and learning. The paper preliminarily analyzed the motivation and content of student-centered teaching idea, and explored the teaching and learning method in the practical course combining "3S" technology (which is the shorter form of remote sensing (RS), global positioning system (GPS) and geographic information systems (GIS)).
\end{abstract}

${ }^{*}$ Corresponding Author. 


\section{Introduction}

Modern concepts in education and teaching increased emphasis on developing students' cognitive structure building, enhancing subjective initiative, and motivating active emotion in studying. Stress the need for let learning to become subjectivity, initiative, creative activities, continuously generating, developing and improving ${ }^{[1]}$. In GIS specialty of university, how to improve effectively scientific research quality and practical skills is an urgent problem to be solved. "3S" (which is the shorter form of remote sensing (RS), global positioning system (GPS) and geographic information systems (GIS)) has become a important integrated technologies on earth science. Based on many years of practice teaching experiences, the aim of practical course named as " $3 S$ " integrated technique is to cultivate the abilities of field surveying, spatial information extracting, and spatial data analyzing, and to enhancing students’ subjective initiative as well.

\section{Motivation for the idea of the student-centered teaching}

Practical course is one of teaching specialties on earth sciences courses at university.. Students' practical operation skills can be cultivated by indoor and outdoor practices. Additionally, the student-centered practical course can fully mobilize students' subjectivity, improve the effect of cultivating practical skill, and further cultivate students' cooperation and creative ability.

(1). The course can cultivate students' subjective initiative. In the course, students were set as a center place, and they were fully mobilized to actively participate in the practice and master all kinds of skills as soon as possible.The previous practical course teaching had two main problem. Firstly, students always only referred to a practice case content designed by teachers according to the teaching guide manuals. Secondly, few students could keep on following teachers for studying knowledge related to the practical course, while most students' considered the courses as a tour experience, lacking of teachers guidance. Therefore, the previous practical course could not mobilize students' subjective initiative. However, the student-centered practical course can avoid the above mentioned problems and improve students' initiative and activeness.

(2). The course can cultivate students' cooperation ability. In the course, students select suitable members to build a group, according to their respective professional advantages. In addition, the members have a clear division of labor and cooperated with each other to obtain valuable research results.

(3). The course can cultivate students' innovation ability. The student-centered course set up creative thinking environment for students and stimulated them to explore issues of interest and enthusiasm. Throughout personally finding problem, analyzing problem, and solving problem during the course, the practical teaching motivated students' interest for science research.

\section{Teaching idea of the student-centered practical course}

In practical course, student-centered idea mainly includes improving relationship between teachers and students, building students' teamwork, and respecting differences among students.

(1). Improving relationship between teachers and students by establishing an equal cooperative relationship. The teachers in Oxford University often said "The smoke from the tutor or supervisor continuously nurtures his student until the fire in the mind of the student is ignited"[2], which means that teachers should try their best to guide students. In the practical course, teacher only taught the essential knowledge, and mainly encouraged students to think independently, make personal practical course plan, and find problem. Consequently, the course can promote students' motivation to learn so that the students can solve practical problems in the self-conscious environment.

(2). Building students' teamwork by paying attention to students' team cooperation. Building research teams is an important approach to cultivate cooperation relationship. In the team, each member has clearly assigned tasks to finish a same mission. Consequently, students can study notions of cooperation and competitions. . In addition, students can study new knowledge, promote exchange with each other, and experience the team happiness and significance of teamwork during the course.

(3). Respecting student differences by respecting their professional advantages and disadvantages. For students with different professional background, teachers should pay attention to the general teaching aim and individual cultivation, and thus satisfy different need and display their respective advantages in a practice program. For example, students majored in physiography are good at analyzing rules for 
regional differences; students majored in GIS have the advantage of computer operation and spatial analysis; and students majored in human geography can analyze the social development by using remote sensing image, and so on.

\section{Teaching process of the student-centered practical course}

The field practical course base is located in Yanqing County, Beijing, China, which is also the study area. The course is divided into two periods of indoor and outdoor practices. The detailed process includes building practice groups, finishing indoor work, finishing outdoor work, and summarizing the whole practice.

(1). Building practice groups. Firstly, teachers tell students all the things about the practical course, such as analyzing data, working in the field, writing practical report, and so on. Students in the practical course are mainly majored in physiography, GIS, and human geography. They can select freely different members to form a group with 5-7 persons. Each group has an oral report and exhibit own achievements when the practical course finish.

(2). Finishing indoor work. The indoor work include two parts. Firstly, each student begin to analyze image data of the study area according to textbook guide. The work is consisting of geometric correction, visual interpretation, pre-classification, change detection, and so on. Additionally, each group is asked to collect information of land use/land cover classification, constructing image interpretation key, and field observation and sampling. Secondly, each group analyzes the field image data to obtain mapping by using spatial analysis function in GIS software.

(3). Finishing outdoor work. Each group starts to survey field topography of the study area, operates field instruments, and investigates field mapping. When the problem comes during carrying out pre-classification for the study region, each group will select the field survey route, conduct ground surveying and mapping, and establish a database of field survey with the help of other groups, according to the principles including "screening typical area", "accessibility of route", and "data sharing".

(4). Summarizing the whole practice. The step is that teachers begin to evaluate the reports each group submit which are comprised of group comprehensive report, personal report, and group featured achievement when the practical course finishes. Group comprehensive report would show how to establish field sampling database, and carry out thematic map, analysis accuracy, and extract information of remote sensing image. Personal report would exhibit how to analyze image and field data available in each group. Group featured achievement would display innovation work which the whole team finishes.

\section{Summary}

The idea of student-centered practical course reflect two aspects for teachers and students, as follows:

(1). For students, teachers should prepare all sections of the practical course to make sure that students can participate in every step. Firstly, students selects freely members to build a group, which fully respects students' wishes. For guiding to build the group, teachers need to introduce the detailed process, and hand out textbook guide to make students know the hardship and complexity of the practice work. Secondly, the indoor work has a clear division of labour. Because there are heavy workload and difficult technology for RS and GIS softwares, all members need to cooperate with each other to finish every group assignment. Therefore, teachers ask students to exercise the software operation according to textbook guide. Thirdly, students can select independent routes in the field survey. Before that, students are asked to exercise instruments used in the practical course. Fourthly, the practice reports promote students' cooperation and competion. When the course finished, each group would display the whole processes of solving problem and innovation thinking. According to teachers' evaluation, each student would know personal deficiency. The excellent reports would be further recommended to conduct full manuscripts for submission.

(2). For teachers, they become as designers, tutors, and controller from teachers in the course. Firstly, the whole practice process has exact plans in order to make students participate actively in the course. Secondly, tutors only answer the technology questions besides teaching simply practical steps and methods in the whole course. Thirdly, controllers mainly control practice schedule and quality.

In sum, the student-centered practical course is the most important specialty in all earth science courses. The student-centered idea can strengthen students' positivity and cultivate their ability of practice, synthesis, innovation and cooperation. 
The International Archives of the Photogrammetry, Remote Sensing and Spatial Information Sciences, Volume XL-6, 2014 ISPRS Technical Commission VI Symposium, 19 - 21 May 2014, Wuhan, China

\section{References}

[1] Sun, L.M., Xiao, H., Nie, Y.J., Lin, Q., 2008. Cultivation of research-based study ability in college english teaching and learning. Educator, 36, pp. 86-87.

[2] Chen, X.Y., 2009. Victoria uinversity teaching strategy for the major of film and some reflection. Movie review, 1, pp. 71-72.

\section{Acknowledgments}

The paper was jointly funded by the National Science Foundation for Fostering Talents in Basic Research of the National (Grant No. 07305035) and the Open Research Fund of State Key Laboratory of Information Engineering in Surveying, Mapping and Remote sensing. 